\title{
Study of the properties of lubricating oils obtained from biodiesel
}

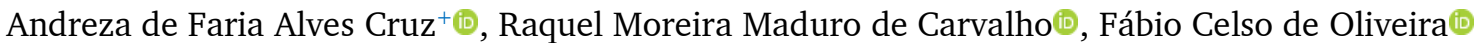

Centro Universitário de Viçosa (Univiçosa), 3815 Maria de Paula Santana Av, Viçosa, Minas Gerais, Brazil.

+Corresponding author: Andreza de Faria Alves Cruz, Phone: +55 319 9558-1602 email address: andrezafalvesc@gmail.com

\section{ARTICLE INFO}

Article history:

Received: April 26, 2019

Accepted: December 18, 2019

Published: April 1, 2020

\section{Keywords:}

1. biodiesel

2. engines

3. vegetable oils

4. performance

5. lubricants

6. transesterification

\begin{abstract}
In this work, nine different biodiesels were obtained by transesterification reaction with three types of vegetable oils and three variant alcohols. The objective was to analyze them physicochemically before and after they went to the engine, to know if they had the necessary properties to act as lubricants. Subsequently, the same biodiesels were analyzed in the engine in order to observe the behavior of their dynamic viscosities, to evaluate if they were similar or superior to commercial lubricants. It was

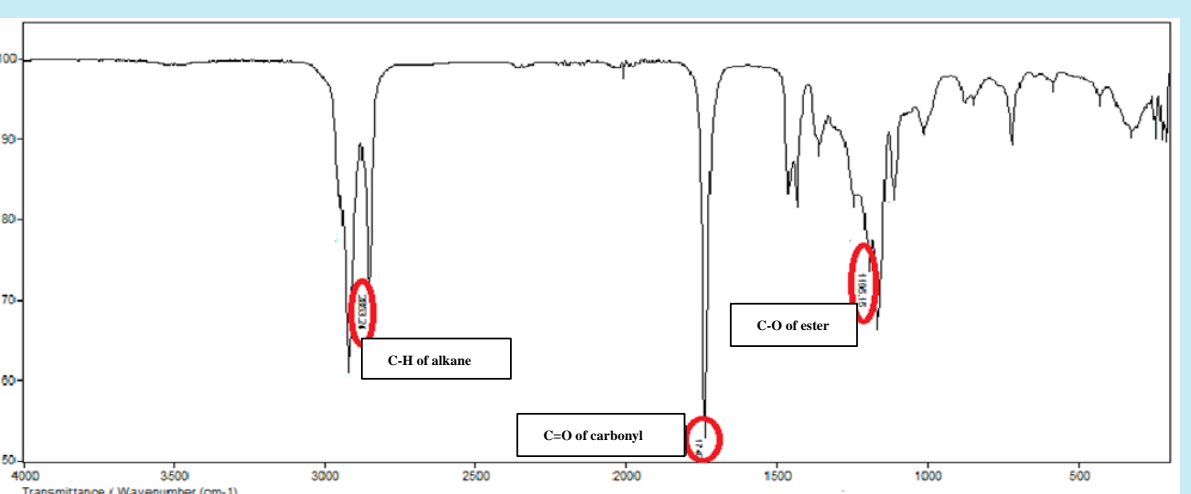

The obtained biodiesels proved to be potential lubricants and could replace the commercial lubricants of the 4-stroke engines.

possible to note that all biodiesel produced are within the National Agency for Petroleum, Natural Gas and Biofuels (ANP) legislation and presented as potential lubricants, due to the kinematic viscosity behavior when compared before and after the engine. These results made them possible replacements for commercial lubricants, besides having greater advantages for the engine and the environment. However, although coconut oil-derived biodiesel has good yields, it is not promising because, at temperatures below $25^{\circ} \mathrm{C}$ tends to solidify, causing short, medium- and long-term engine parts wear.
\end{abstract}

\section{Introduction}

In the last 10 years, the world's energy consumption grew by $2.5 \%$. Oil has been steadily falling, but it is still considered the largest primary source of used energy, although the energy consumption from renewable sources is growing. China has been reducing its energy consumption over the years, but it is still considered the most energy consuming country in the world, importing about $58 \%$ of oil. Following on the list of the world's largest energy consumers, there are the United States, India, Germany and Brazil. Brazil is expected to grow $2.2 \%$ by the year 2040 , with emphasis on renewable energies $(4.5 \%)^{1}$.
It has now become clear that the world's perceptions about renewable energy have changed a lot and are now seen as an outlet to address some needs such as improving energy security, reducing impacts on health and the environment, mitigating greenhouse gas emissions, improving opportunities in the area of education, creation of new labor poles and poverty reduction ${ }^{2}$.

Biodiesel appears as an alternative, since its main application is fuels, because it is free of aromatic compounds and sulfur, an important characteristic in the environmental sector; besides being more economically viable for stimulating agricultural production, reducing importation of oil from other countries. It can be obtained through a mixture of different esters resulting from the 
esterification reaction of fatty acids or transesterification of glycerides ${ }^{3}$.

Several raw materials are used in the production of biodiesel, such as vegetable oils, animal fats and used frying oil. According to the National Petroleum Agency ${ }^{4}$, biodiesel produced in Brazil comes from soybean oil (76.4\%), animal fat (19.8\%), cotton oil (2.2\%) and other vegetable oils (1.6\%).

In addition to using biodiesel as fuel, it can also be used as lubricant. When it acts as a lubricant, it performs much better than commercial lubricants, due to its high lubricating power, higher viscosity and less wear on the engine parts ${ }^{5}$.

For the development of a lubricant, specified physicochemical properties must be obtained, such as viscosity, resistance to corrosion, total acidity index, pour point, chemiluminescence, among others. In the case of biolubricant esters which are derived from organic esters, hydrolytic, oxidative and thermal stabilities must be obtained ${ }^{6}$.

The lubricating oil used in the engine must meet all lubrication needs in the different tribological pairs found in the engine ${ }^{7}$. Thus, it can be stated that the ignition quality of the fuel, the types of hydrocarbons present in the fuel and the presence of impurities or additives in it affect the performance of the engine lubricating oil.

In this study, the synthesis of biodiesel from vegetable oils was proposed, as well as the analyses of their physicochemical properties to act as lubricants, evaluating the kinematic viscosity before and after the sample in the engine to verify if the performance of biodiesel as a lubricant is similar to or higher than commercial lubricants.

\section{Experimental}

\subsection{Production of biodiesel}

For the transesterification reactions, the methodology described by Geris et al. ${ }^{8}$ was used, which initially consisted of the preparation of an intermediate through the mixture of potassium hydroxide and varying alcohols, such as methanol, ethanol and isopropyl alcohol, under heating at $45^{\circ} \mathrm{C}$ and constant stirring until complete dissolution of the solid. Later, the intermediate was mixed with the oils, which were also varied in the reaction as: being coconut oil, castor oil and rice oil. They were commercially purchased, and the reaction were carried out at $45{ }^{\circ} \mathrm{C}$ for $10 \mathrm{~min}$. Afterwards, the biodiesel was elaborated, pouring the previous mixture and separating it through a separation funnel, isolating the biodiesel and the glycerin, and the excesses of base and alcohol. The biodiesel was treated with distilled water at $70{ }^{\circ} \mathrm{C}$, followed by aqueous solution of hydrochloric acid $0.5 \% \mathrm{v} / \mathrm{v}$ until it reached neutral $\mathrm{pH}$. Finally, moisture was withdrawn with anhydrous magnesium sulfate under constant stirring for $15 \mathrm{~min}$.

Thus, nine combinations of reactions were performed: coconut oil and methyl alcohol, castor oil and methyl alcohol, rice oil and methyl alcohol, coconut oil and ethyl alcohol, castor oil and ethyl alcohol, rice and ethyl alcohol, coconut oil and isopropyl alcohol, castor oil and isopropyl alcohol and rice oil and isopropyl alcohol.

\subsection{Biodiesel yield}

Regarding the mass yield of biodiesel produced through the basic transesterification process, the quantity of biodiesel obtained from the ratio of 1:6 with the highest amount of oleic acid was accounted for. Yield was evaluated from the alcohol and vegetable oil used in the reaction.

All reactions were performed in triplicate, as approximately $500 \mathrm{~mL}$ were required for further use in the engine.

\subsection{Validation of the lubrication property of the lubricants in the internal combustion engine by the kinematic viscosity analysis}

The samples were assayed in a seven-stroke gasoline four-stroke engine, Manual Start NMG70, at Univiçosa Physics Laboratory. Initially, it was necessary to use $500 \mathrm{~mL}$ of commercial fuel to start the engine. Subsequently, each sample was for 3 nonconsecutive $h$ in the motor.

For the engine to run, $500 \mathrm{~mL}$ of each synthesized biodiesel were used, according to routes previously described in the methodology. It is important to note that when below this amount, the motor does not run to rotate the sample.

\subsection{Physicochemical characterization of biodiesel}

All the biodiesel obtained were characterized by $\mathrm{pH}$, specific mass, total acidity index, moisture content, kinematic viscosity, plus metal detection tests and infrared. All analyzes were performed in 
triplicate, except for the viscosity that was performed five times.

\subsubsection{Appearance and color}

In order to characterize the biodiesel in relation to aspect and color, a preliminary analysis was carried out looking for the presence of visual impurities, such as suspended materials, sediments or any turbidity in the sample, which may be due to the presence of water. In the absence of any of these contaminants, biodiesel was classified as clear and free of impurities, according to NBR $14954{ }^{9}$.

\subsection{2. $p H$}

The $\mathrm{pH}$ was measured with a pHmeter, which can present values ranging from 0 to 14 , indicating acidity, neutrality or basicity of the medium. For biodiesel, the $\mathrm{pH}$ must be 7 , that is neutral ${ }^{10}$.

\subsubsection{Specific mass}

To determine the specific mass, a $25 \mathrm{~mL}$ glass pycnometer was used. First the empty pycnometer was weighed and written down to its mass. Then it was filled with distilled water, weighed and its mass was noted. Subsequently, the clean and dry pycnometer was filled with biodiesel, being again weighed with its mass noted, according to NBR $7148 / 14065^{11}$. The specific mass was calculated with Eq. 1:

$\rho=\frac{m}{v}$

\subsubsection{Total acidity index}

To calculate the acid number, it was necessary to measure a mass of approximately $10 \mathrm{~g}$ of biodiesel in a $125 \mathrm{~mL}$ Erlenmeyer flask. A mixture of ethyl alcohol and ethyl ether in the ratio of 2:1 by volume was prepared. Subsequently, $25 \mathrm{~mL}$ of this mixture was added to the Erlenmeyer flask along with 3 drops of phenolphthalein. Titration of the solution was then carried out with $0.02 \mathrm{~mol} \mathrm{~L}^{-1}$ sodium hydroxide, and the blank was titrated, that is, $25 \mathrm{~mL}$ of the mixture of ethyl ether and ethyl alcohol together with 3 drops of phenolphthalein without the presence of biodiesel, according to NBR $14448{ }^{12}$. The calculation of the acid number is performed by Eq. 2:
$\mathrm{Ia}=\frac{\left(V_{\text {spent }}-V_{\text {blank reaction }}\right) \times f \times 5.61}{m_{\text {oil }}}$

\subsubsection{Moisture content}

To determine the moisture content of the biodiesel, a greenhouse, in which a mass of approximately $20 \mathrm{~g}$ of biodiesel was placed in the crucible free of moisture, was used and then weighed.

The sample was then placed in an oven, with temperature at $100{ }^{\circ} \mathrm{C}$ for $24 \mathrm{~h}$. After this time, the sample was cooled in a desiccator and the sample was weighed again until the value remained constant, thus obtaining the moisture content by the difference between the initial and final masses, through Eq. 3, according to ASTMD $6304^{13}$.

Moisture content $=\mathrm{P}_{\mathrm{i}}-\mathrm{P}_{\mathrm{f}}$

$P_{i}$ is the initial weight of the crucible with biodiesel and $\mathrm{P}_{\mathrm{f}}$ is the final weight of the crucible with biodiesel.

\subsubsection{Kinematic viscosity}

The kinematic viscosity was determined with the aid of a pipette, adding $15 \mathrm{~mL}$ of sample to the viscometer through the ventilation tube, and waited 5-10 min to equilibrate the liquid temperature to $25^{\circ} \mathrm{C}$. With the aid of the pipettor fitted to the capillary tube, the fluid was suctioned up to above the upper measurement mark, according to NBR $10441^{4}$. The kinematic viscosity can be calculated by Eq. 4:

$v=\mathrm{K} \times \mathrm{t}$

Where $v$ is the kinematic viscosity of the sample (in $\mathrm{mm}^{2} \mathrm{~s}^{-1}$ ), $\mathrm{K}$ is the viscometer constant calculated for a known fluid (in $\mathrm{mm}^{2} \mathrm{~s}^{-2}$ ) and $\mathrm{t}$ is the average of the time the sample took to move from the measurement mark top to bottom.

\subsubsection{Qualitative test for metal detection}

For the qualitative test of metal detection, electromagnetic magnets were used. The magnets were approximated to the biodiesel samples. In case of attraction, it indicates the presence of metals and if nothing happens, absence ${ }^{8}$.

\subsubsection{Infrared}


The spectra were collected in the Perkin-Elmer FT-IR 1000 spectrophotometer in the range of 4000 to $200 \mathrm{~cm}^{-1}$ in the Department of Chemistry UFV and were made in ATR.

\section{Results and Discussion}

\subsection{Characterization of biodiesel}

The biodiesel characterization was carried out from the results of some parameters, through which the quality of the biodiesel produced can be evaluated. The quality has a direct relation with the operation and the life of an engine, so it was possible to ascertain the quality of the biodiesel produced.

According to National Agency for Petroleum, Natural Gas and Biofuels regulation 25/2014 ${ }^{4}$, in order to the product obtained to be considered a biodiesel, it must comply with some rules such as: be clear and free of impurities; have neutral $\mathrm{pH}$; have density, total acidity index, moisture content and kinematic viscosity within the established limits.

Tables 1, 2 and 3 present the methodologies used in each parameter, the results obtained by the analysis of coconut, castor and rice biodiesel, respectively, following the limits established by the Brazilian legislation ${ }^{4}$.

Table 1. Results obtained for acidity index tests $\left(\mathrm{mg} \mathrm{KOH} \mathrm{g}^{-1}\right)$, relative density $\left(\mathrm{kg} \mathrm{m}^{-3}\right)$, moisture content ( $\mathrm{mg}$ $\mathrm{kg}^{-1}$ ), followed by the Brazilian legislation ${ }^{4}$.

\begin{tabular}{|c|c|c|c|c|c|}
\hline Parameters & $\begin{array}{c}\text { Methodology } \\
\text { adopted }\end{array}$ & BCOM & BCOE & BCOI & $\begin{array}{c}\text { NPA Resolution, } \\
\mathbf{2 0 0 4}\end{array}$ \\
\hline Aspect & NBR 14954 & $\begin{array}{c}\text { Clean and free of } \\
\text { impurities }\end{array}$ & $\begin{array}{c}\text { Clean and free of } \\
\text { impurities }\end{array}$ & $\begin{array}{c}\text { Clean and free of } \\
\text { impurities }\end{array}$ & $\begin{array}{c}\text { Clean and free of } \\
\text { impurities }\end{array}$ \\
\hline $\begin{array}{c}\text { Specific } \\
\text { mass }\end{array}$ & NBR 7148/14065 & $868.432 \pm 0.002$ & $867.012 \pm 0.005$ & $872.476 \pm 0.003$ & 850 to 900 \\
\hline $\begin{array}{c}\text { Specific } \\
\text { relative } \\
\text { mass }\end{array}$ & - & $0.835 \pm 0.002$ & $0.794 \pm 0.005$ & $0.780 \pm 0.003$ & - \\
\hline $\begin{array}{c}\text { Acidity } \\
\text { Index level }\end{array}$ & NBR 14448 & $0.090 \pm 0.008$ & $0.059 \pm 0.008$ & $0.042 \pm 0.007$ & $<0.5$ \\
\hline $\begin{array}{c}\text { Moisture } \\
\text { content }\end{array}$ & ASTMD 6304 & $197.000 \pm 0.003$ & $189.09 \pm 0.02$ & $190.73 \pm 0.03$ & $<200.0$ \\
\hline
\end{tabular}

BCOM - Biodiesel coconut oil with methanol; BCOE - Biodiesel coconut oil with ethanol; BCOI - Biodiesel coconut oil with isopropanol; BCAOM - Biodiesel castor oil with methanol; BCAOE - Biodiesel castor oil with ethanol; BCAOI - Biodiesel castor oil with isopropanol; BROM - Biodiesel rice oil with methanol; BROE - Biodiesel rice oil with ethanol; BROI - Biodiesel rice oil with isopropanol.

For biodiesel produced from methanol, all are classified as clear and free of impurity, as specified by Brazilian legislation. ${ }^{4}$, since they have no impurities or turbidity, so biodiesel is within the cited specification.

The specific mass values obtained at $20{ }^{\circ} \mathrm{C}$ for all biodiesel are within the limits of 850 to $900 \mathrm{~kg} \mathrm{~m}^{-3}$ established by NBR $7148 / 14065^{4}$. The values were within the range required by the Brazilian legislation $^{4}$, which indicates high purity of the products obtained.

Considering that Resolution $\mathrm{n}^{\circ} 255$, dated November 15, 2003, indicates that the maximum limit of acidity index is $0.50 \mathrm{mg} \mathrm{KOH} \mathrm{g}^{-1}$ of oil, so the values observed in Tab. 1 are within the allowed values, which is a good result, since an acidity index above the allowed one leads to the aging of the lubricant and it wears the parts of the motor in the long term.

For the analysis of the moisture content, Eq. 3 was used, according to methodology. It can be observed that all values obtained for biodiesel from methanol, in Tab. 1, were within the limit of $0.5 \mathrm{mg} \mathrm{kg}^{-1}$ required by the Brazilian legislation ${ }^{4}$, which is important since the water content above the allowance impairs the property of the lubricant and oxidizes the engine parts over time.

The relative specific mass is given by the specific mass of the biodiesel in relation to the specific mass of the water, both obtained experimentally. Even though a limit is not specified $^{4}$, as the specific masses were within the limit, consequently, the relative specific masses are too. 
Table 2. Results obtained for acidity index tests $\left(\mathrm{mg} \mathrm{KOH} \mathrm{g}^{-1}\right)$, relative density $\left(\mathrm{kg} \mathrm{m}^{-3}\right)$, moisture content $(\mathrm{mg}$ $\mathrm{kg}^{-1}$ ), followed by the Brazilian legislation ${ }^{4}$.

\begin{tabular}{|c|c|c|c|c|c|}
\hline Parameters & $\begin{array}{c}\text { Methodology } \\
\text { adopted }\end{array}$ & BCAOM & BCAOE & BCAOI & $\begin{array}{c}\text { NPA Resolution, } \\
\mathbf{2 0 0 4}\end{array}$ \\
\hline Aspect & NBR 14954 & $\begin{array}{c}\text { Clean and free of } \\
\text { impurities }\end{array}$ & $\begin{array}{c}\text { Clean and free of } \\
\text { impurities }\end{array}$ & $\begin{array}{c}\text { Clean and free of } \\
\text { impurities }\end{array}$ & $\begin{array}{c}\text { Clean and free of } \\
\text { impurities }\end{array}$ \\
\hline $\begin{array}{c}\text { Specific mass } \\
\begin{array}{c}\text { Specific } \\
\text { relative mass }\end{array}\end{array}$ & NBR 7148/14065 & $869.352 \pm 0.002$ & $898.540 \pm 0.003$ & $861.676 \pm 0.002$ & 850 a 900 \\
\hline $\begin{array}{c}\text { Acidity Index } \\
\text { level }\end{array}$ & NBR 14448 & $0.045 \pm 0.006$ & $0.20 \pm 0.02$ & $0.070 \pm 0.005$ & - \\
\hline $\begin{array}{c}\text { Moisture } \\
\text { content }\end{array}$ & ASTMD 6304 & $189.08 \pm 0.02$ & $190.76 \pm 0.02$ & $189.09 \pm 0.02$ & $<0.5$ \\
\hline
\end{tabular}

BCAOM - Biodiesel castor oil with methanol; BCAOE - Biodiesel castor oil with ethanol; BCAOI - Biodiesel castor oil with isopropanol.

In Tab. 2, it can be observed that all the biodiesels obtained through the castor oil were also clear and free of impurities.

The specific masses were within the range of 850 to $900 \mathrm{~kg} \mathrm{~m}^{-3}$, indicating high purity of these products obtained by the transesterification reaction. In addition, the specific mass of a biodiesel is directly linked to the molecular structure of its molecules. The longer the carbon chain of the ester, the greater its specific mass, but the value will decrease the higher the numbers of unsaturated bonds present in the molecule. The presence of impurities may also influence the specific mass. As observed, ethanol has a higher carbon chain than methanol, so its specific mass is higher. In contrast, isopropanol has branching; consequently, there is a decrease in its specific mass, as stated by Lace et al. ${ }^{14}$.

The acidity index was also within the Brazilian legislation ${ }^{4}$ limit, being less than $0.5 \mathrm{mg} \mathrm{KOH} \mathrm{g}^{-1}$, with very low standard deviations, which corresponds to the accuracy of the triplicate analyzes.

Regarding the moisture content, the values obtained were lower than $200 \mathrm{mg} \mathrm{kg}^{-1}$, indicating that all biodiesel obtained from castor oil are within the limits of the Brazilian legislation ${ }^{4}$.

Table 3. Results obtained for acidity index tests $\left(\mathrm{mg} \mathrm{KOH} \mathrm{g}^{-1}\right)$, relative density $\left(\mathrm{kg} \mathrm{m}^{-3}\right)$, moisture content (mg $\mathrm{kg}^{-1}$ ), followed by standard legislation ${ }^{4}$.

\begin{tabular}{|c|c|c|c|c|c|}
\hline Parameters & $\begin{array}{c}\text { Methodology } \\
\text { adopted }\end{array}$ & BROM & BROE & BROI & $\begin{array}{c}\text { NPA Resolution } \\
\mathbf{2 0 0 4}\end{array}$ \\
\hline Aspect & NBR 14954 & $\begin{array}{c}\text { Clean and free of } \\
\text { impurities }\end{array}$ & $\begin{array}{c}\text { Clean and free of } \\
\text { impurities }\end{array}$ & $\begin{array}{c}\text { Clean and free of } \\
\text { impurities }\end{array}$ & $\begin{array}{c}\text { Clean and free of } \\
\text { impurities }\end{array}$ \\
\hline $\begin{array}{c}\text { Specific mass } \\
\text { Specific relative } \\
\text { mass }\end{array}$ & NBR 7148/14065 & $871.412 \pm 0.014$ & $876.768 \pm 0.018$ & $866.012 \pm 0.021$ & 850 to 900 \\
\hline $\begin{array}{c}\text { Acidity Index } \\
\text { level }\end{array}$ & - & $0.83 \pm 0.03$ & $0.84 \pm 0.04$ & $0.82 \pm 0.02$ & - \\
\hline NBR 14448 & $0.034 \pm 0.003$ & $0.059 \pm 0.002$ & $0.037 \pm 0.005$ & $<0.5$ \\
\hline Moisture content & ASTMD 6304 & $178.11 \pm 0.03$ & $178.92 \pm 0.03$ & $198.52 \pm 0.03$ & $<200.0$ \\
\hline
\end{tabular}

BROM - Biodiesel rice oil with methanol; BROE - Biodiesel rice oil with ethanol; BROI - Biodiesel rice oil with isopropanol.

Through Tab. 3, it was possible to observe that all the biodiesels obtained with isopropanol were clear and free of impurities.

For the specific mass, the values were within the limit of 850 to $900 \mathrm{~kg} \mathrm{~m}^{-3}$ according to the legislation ${ }^{4}$, indicating the high purity of these obtained biodiesels. In the same way, the ethanol has greater carbonic chain than the methanol, therefore, greater specific mass; while the isopropanol has branching, then it has a lower specific mass, according to Lace et al. ${ }^{14}$. 
The acidity index was also within the limit of $0.5 \mathrm{mg} \mathrm{KOH} \mathrm{g}{ }^{-1}$, presenting low values, which is a good sign since it does not indicate wear of the engine parts.

Regarding the moisture content, the values were within the limit of $200 \mathrm{mg} \mathrm{kg}^{-1}$ of the Brazilian legislation ${ }^{4}$. It is very important that the analyzes of moisture content are within the limit described by the National Agency for Petroleum, Natural Gas and Biofuels, since, according to Lace et al. ${ }^{14}$, water promotes the hydrolysis of biodiesel resulting in free fatty acids, contributing to the proliferation of microorganisms, equipment corrosion and deposition of sediments. In addition, the presence of water contributes to the increase in acidity, which is not desired.

\subsection{Biodiesel yield}

The yield calculation was useful to verify which vegetable oil and alcohol had the best yield in obtaining biodiesel, that is, how much was converted from reagent (vegetable oil) to product (biodiesel).

Tables 4, 5 and 6 below indicate these yields:

Table 4. Yield for biodiesel derived from coconut oil.

\begin{tabular}{|c|c|c|c|}
\hline \% biodiesel & BCOM & BCOI & BCOE \\
\hline Reaction 1 & 60 & 60 & 58 \\
\hline Reaction 2 & 75 & 66 & 63 \\
\hline Reaction 3 & 89 & 70 & 55 \\
\hline
\end{tabular}

Some studies by Nascimento, Vasconcelos and Azevedo $^{15}$ show a technique of microwave optimization, leading to a yield of approximately $100 \%$.

The biodiesel obtained by means of coconut oil with isopropanol presented values higher than expected, although there are no comparisons with the literature. However, according to Geris et al. ${ }^{8}$, isopropanol is not as viable for transesterification reaction due to its higher carbon chain and greater branching when compared to the other alcohols used.

Regarding biodiesel derived from coconut oil with isopropanol, the values were within the expected range, as described by Shimada et al. ${ }^{16}$, from 45 to $80 \%$, a little lower than methanol due to its higher carbon chain, less toxic than it.

Geris et al. ${ }^{8}$ showed that biodiesel obtained from methanol yields between 58 and $89 \%$, due to the lower carbon chain that facilitates the transesterification reaction; followed by ethyl alcohol in yields between 55 and $75 \%$, being even less toxic. The higher the carbon chains and the ramifications, the lower the yields of biodiesel due to the greater difficulty of reacting. In relation to coconut oil, for Dias, Ferraz e Almeida ${ }^{17}$ the yields with methanol are around 60 to $90 \%$, while with ethanol, for Shimada et al. ${ }^{16}$, they vary between 45 and $80 \%$.

Table 5. Yield values for biodiesel derived from castor oil.

\begin{tabular}{|c|c|c|c|}
\hline $\begin{array}{c}\% \\
\text { biodiesel }\end{array}$ & BCAOM & BCAOI & BCAOE \\
\hline Reaction 1 & 65 & 45 & 56 \\
\hline Reaction 2 & 87 & 47 & 51 \\
\hline Reaction 3 & 93 & 74 & 64 \\
\hline
\end{tabular}

Table 5 shows that the biodiesel obtained through castor oil with methanol presented good yields, according to the range of 60 to $96 \%$ specified by Dias, Ferraz e Almeida ${ }^{17}$.

For biodiesel derived from castor oil with isopropanol, it is believed that the values were low as expected by the chemical explanation regarding the amount of carbonic chain and branching, as explained by Geris et al. ${ }^{8}$.

The biodiesel obtained by means of castor oil with ethanol presented yield between the limit expected by Dias, Ferraz e Almeida ${ }^{17}$, from 40 to $75 \%$. As shown in Tab. 4, yields of biodiesel obtained from coconut oil by methanol were considered as expected, since according to Dias, Ferraz e Almeida ${ }^{17}$, a yield of 60 to $90 \%$ for biodiesel from coconut oil from methanol.

Table 6. Yield values for biodiesel derived from rice oil.

\begin{tabular}{|c|c|c|c|}
\hline \% biodiesel & BROM & BROI & BROE \\
\hline Reaction 1 & 83 & 46 & 54 \\
\hline Reaction 2 & 71 & 53 & 66 \\
\hline Reaction 3 & 81 & 64 & 96 \\
\hline
\end{tabular}

Table 6 shows that biodiesel obtained from rice oil with methanol presented high values, as expected by Charoenchaitrakool and Thienmethangkoon ${ }^{18}$, from 70 to $95 \%$.

The biodiesel obtained through the rice oil with isopropanol presented low yields, but already expected according to the chemical explanation of the carbon chain, as suggested by Geris et al. ${ }^{8}$.

For the biodiesel obtained by means of the rice oil with ethanol, the yields were within the expected, with highlight to the $3^{\text {rd }}$ reaction with 
yield of $96 \%$, higher than expected by the limit of 50 to $80 \%$ of Charoenchaitrakool and Thienmethangkoon ${ }^{18}$.

In relation to the performance of biodiesel in the engine, the yield does not directly influence. However, good yields are feasible because of the amount of $500 \mathrm{~mL}$ needed for the lubricant to run on the engine. A low yield means having to perform a greater amount of reaction to achieve what is required for the internal combustion engine, making the process more expensive and exhausting.

\subsection{Validation of the lubrication property of the} lubricants in the internal combustion engine by the kinematic viscosity analysis
It was observed that the engine maintained the correct operating temperature, since a laser thermometer was used to carry out the temperature measurements during operation, so that there was no overheating of the engine components. Also, no smoke or anomaly was observed during or after the tests.

Kinematic viscosity analyzes are listed in Tab. 7,8 and 9 , both before and after each sample for $3 \mathrm{~h}$. The analyses were performed in quintuplicate and the results were given by the mean.

Analyzes before the engine will be called $\mathrm{BE}$ and after engine AE.

Table 7. Kinematic viscosity results in biodiesel derived from coconut oil

\begin{tabular}{|c|c|c|c|c|c|c|}
$\begin{array}{c}\text { Kinematic viscosity } \\
\left(\mathrm{mm}^{2} \mathbf{s}^{-1}\right)\end{array}$ & BOCM $(\mathbf{B E})$ & BOCI $(\mathbf{B E})$ & BOCE $(\mathbf{B E})$ & BOCM $(\mathbf{A E})$ & BOCI $(\mathbf{A E})$ & BOCE $(\mathbf{A E})$ \\
\hline Average & $2.600 \pm 0.002$ & $5.980 \pm 0.004$ & $6.000 \pm 0.007$ & $6.400 \pm 0.004$ & - & $6.500 \pm 0.008$ \\
\hline
\end{tabular}

In Tab. 7 , it was possible to observe that the biodiesel obtained through coconut oil before the engine showed satisfactory results, within the range of 3.0 to $6.0 \mathrm{~mm}^{2} \mathrm{~s}^{-1}$ of the $\mathrm{NBR}^{4}$. Only the biodiesel obtained from coconut oil with methanol showed below-expected value, which is detrimental since lubricant that has low viscosity may not sufficiently protect engine parts, increasing parts wear, causing more friction and oxidizing faster, as explained by Farias et al. ${ }^{5}$.The viscosity values after the engine increased, but not excessively, which was expected due to the oxidation of the biodiesel in the engine.

Table 8. Result of kinematic viscosity in biodiesel derived from castor oil.

\begin{tabular}{|c|c|c|c|c|c|c|}
\hline $\begin{array}{c}\text { Kinematic viscosity } \\
\left(\mathbf{m m}^{2} \mathbf{s}^{-1}\right)\end{array}$ & BCAOM $(\mathbf{B E})$ & BCAOI $(\mathbf{B E})$ & BCAOE $(\mathbf{B E})$ & BCAOM (AE) & BCAOI (AE) & BCAOE (AE) \\
\hline Average & $6.01 \pm 0.01$ & $5.80 \pm 0.01$ & $6.200 \pm 0.003$ & $11.10 \pm 0.01$ & - & $22.60 \pm 0.02$ \\
\hline
\end{tabular}

From Tab. 8, it was possible to observe that the biodiesel obtained through castor oil was within the limits of standard legislation ${ }^{4}$, except for biodiesel from castor oil with ethanol, which presented a value above the limit of $6.0 \mathrm{~mm}^{2} \mathrm{~s}^{-1}$. A viscosity above the limit is detrimental because some parts of the engine do not receive the necessary flux to form the lubricating film, which can result in more wear, accelerating the oxidation and shortening the life of the equipment, as explained by Farias et al..$^{5}$. Regarding the biodiesel analyzed after the engine, the kinematic viscosity values increased, but not excessively, as expected.

Table 9. Kinematic viscosity analysis in biodiesel derived from rice oil.

\begin{tabular}{|c|c|c|c|c|c|c|}
\hline $\begin{array}{c}\text { Kinematic viscosity } \\
\left(\mathbf{m m}^{\mathbf{2}} \mathbf{s}^{-1}\right)\end{array}$ & BROM (BE) & BROI $(\mathbf{B E})$ & BROE $(\mathrm{BE})$ & BROM (AE) & BROI (AE) & BROE (AE) \\
\hline Average & $6.10 \pm 0.01$ & $3.60 \pm 0.01$ & $8.90 \pm 0.02$ & $5.14 \pm 0.01$ & $10.12 \pm 0.01$ & - \\
\hline
\end{tabular}

From Tab. 9, it was possible to observe that the biodiesel derived from rice oil were within the limits of the Brazilian legislation ${ }^{4}$, except for the rice oil with ethanol that presented divergent values, well above the expected, being considered a lubricant able to wear the parts of the engine and cause oxidation in a shorter time. After the engine, the results are also as expected, with kinematic viscosity increasing.

Biodiesel from coconut oil with isopropanol, castor oil with isopropanol, and rice with ethanol were not analyzed in the engine because of their 
low reaction yields, making it impossible to produce more due to the quantity of reagents available.

\subsection{Qualitative test for the detection of metals}

The metal detection test analyses are listed in Tabs. 10, 11 and 12 below. They were performed in triplicate and the results were given by the average.

Table 10. Analysis of the presence of metals in biodiesel derived from coconut oil.

\begin{tabular}{|c|c|c|c|}
\hline $\begin{array}{c}\text { Presence or } \\
\text { absence of metals }\end{array}$ & BOCM & BOCI & BOCE \\
\hline Average & Absent & Absent & Absent \\
\hline
\end{tabular}

Table 11. Analysis of the presence of metals in biodiesel derived from castor oil.

\begin{tabular}{|c|c|c|c|}
\hline $\begin{array}{l}\text { Presence or } \\
\text { absence of metals }\end{array}$ & BORM & BORI & BORE \\
\hline Average & Absent & Absent & Absel \\
\hline
\end{tabular}

Table 12. Analysis of the presence of metals in biodiesel derived from rice oil.

\begin{tabular}{|c|c|c|c|}
$\begin{array}{c}\text { Presence or } \\
\text { absence of metals }\end{array}$ & BOAM & BOAI & BOAE \\
\hline Average & Absent & Absent & Absent \\
\hline
\end{tabular}

The results obtained in Tabs. 10, 11 and 12 were satisfactory since the presence of metals could impair engine performance ${ }^{5}$. It is important to point out that this is a qualitative analysis. To be sure, it is necessary to carry out more restricted analyses, such as atomic absorption.

\subsection{Infrared}

The major bands for biodiesel are given in Tab. 13.

Table 13. The main infrared bands for the biodiesel obtained.

\begin{tabular}{|c|c|c|c|}
\hline Compounds & $v \mathrm{C}-\mathrm{H}_{\text {alif. }}\left(\mathrm{cm}^{-1}\right)$ & $v \mathrm{C}=\mathrm{O}\left(\mathrm{cm}^{-1}\right)$ & $v \mathrm{C}-\mathrm{O}\left(\mathrm{cm}^{-1}\right)$ \\
\hline BOCM & 2853 & 1740 & 1495 \\
\hline BOCI & 2853 & 1664 & 1395 \\
\hline BOCE & 2853 & - & 1435 \\
\hline BORM & 2854 & 1685 & 1451 \\
\hline BORI & 2853 & - & 1453 \\
\hline BORE & 2853 & 1654 & 1451 \\
\hline BOAM & 2853 & - & 1454 \\
\hline BOAI & 2854 & 1667 & 1460 \\
\hline BOAE & 2853 & 1668 & 1462 \\
\hline
\end{tabular}

From the analysis of the infrared spectra, it was possible to observe in all biodiesel the presence of bands characteristic of carbonyls $(\mathrm{C}=\mathrm{O})$, aliphatic $\mathrm{C}-\mathrm{H}$ and $\mathrm{C}-\mathrm{O}$ ester. According to Barbosa ${ }^{19}$, a band in the range of 1650 to $1750 \mathrm{~cm}^{-1}$ indicates axial deformation of the carbonyl $\mathrm{C}=\mathrm{O}$ bond. In addition, the presence of bands between 2853 and $2854 \mathrm{~cm}^{-1}$ indicates an aliphatic C-H band; and in the range of 1390 to $1500 \mathrm{~cm}^{-1}$ correspond to ester C-O.

In this case, the characteristic bands of aliphatic $\mathrm{C}-\mathrm{H}$ and $\mathrm{C}=\mathrm{O}$ of carbonyl correspond to the starting vegetable oil, whereas the band referring to the ester $\mathrm{C}-\mathrm{O}$ bond indicates the formation of the desired product, biodiesel. In this way, the infrared appears as another way of confirming that the product (biodiesel) was obtained through the starting vegetable oil. In the absence of the ester C-O band, there would be no conversion of triacylglyceride to ester, having only the starting vegetable oil, not biodiesel.

This can be observed in Fig. 1. The other spectra are not shown, since the three characteristic bands, which are the bands to emphasize in the work, are the same for all biodiesels, only occurring displacements due to the alcohol of departure of the reaction. 




Figure 1. BOCM Infrared spectrum

\section{Conclusions}

Nine esters (biodiesels) were synthesized from transesterification reactions, varying the vegetable oils and the starting alcohols. These biodiesels were characterized by physicochemical analyses in order to confirm their formation and the characteristic properties of biodiesel, meeting the requirements of the National Agency for Petroleum, Natural Gas and Biofuels.

The biodiesel obtained also had its kinematic viscosity analyzed before and after the engine, demonstrating a similar profile to commercial engine lubricants, being good substituents.

Although biodiesel produced from coconut oil has good reaction yields, it is not intended to act as lubricants in the engine as it tends to solidify at temperatures below $25{ }^{\circ} \mathrm{C}$ and can cause engine parts to wear with particle adhesion in suspension.

Biodiesel derived from isopropyl alcohol is not economically viable to produce lubricants because of the poor performance to obtain it, and many reactions are necessary to obtain the necessary lubricant for the engine.

However, it was observed that the majority of biodiesel obtained have promising results to act as substituents of commercial lubricants, which fill a gap in the scientific literature.

\section{Acknowledgments}

To Univiçosa - Faculty of Sciences and Technology of Viçosa, for the scholarship of undergraduate research.

\section{References}

[1] Manieniyan, V., Senthilkumar, R., Sivaprakasam, S., Comparative wear analysis in a di diesel engine using diesel and biodiesel, International Journal of Modern Trends in Engineering and Research 2 (1) (2015) 119124.

[2] Stepien, Z., Urzedowska, W., Czerwinski, J., Research on engine lube oil deterioration and emissions of diesel engines with biofuels (RME), Energy and Power 4 (1) (2014) 32-49. https://doi.org/10.4271/201101-1302.

[3] Oliveira, D. M. de, Ongaratto, D. P., Fontoura, L. A. M., Naciuk, F. F., Santos, V. O. B. dos, Kunz, J. D., Marques, M. V., Souza, A. O. de, Pereira, C. M. P. de, Samios, D., Transesterification double step process for biodiesel preparation and its chromatographic characterization: oils and fats in practical organic chemistry, Química Nova 36 (5) (2013) 734-737. https://doi.org/10.1590/S0100-40422013000500021.

[4] ANP. National Agency of Petroleum, Natural Gas and Biofuels. ANP Resolution 45 (2014). http://legislacao.anp.gov.br/?path=legislacao-anp/resolanp/2014/agosto\&item=ranp-45--2014.

[5] Farias, A. M., Santana, J. S., Oliveira Filho, M. F., Santana, J. S., Barbosa, C. R. F., Medeiros, J. T. N., Os combustíveis verdes do brasil - avaliação da lubricidade do biodiesel B5 e óleos de mamona e coco, Holos 3 (27) (2011) 3-17. https://doi.org/10.15628/holos.2011.453.

[6] Wagner, H., Luther, R., Mang, T., Lubricant base fluids based on Renewable Raw Materials. Their Catalytic Manufacture and Modification, Applied 
Catalysis A: General 221 (1-2) (2001) 429-442. https://doi.org/10.1016/S0926-860X(01)00891-2.

[7] Caines, A. J., Haycock, R. F., Automotive Lubricants Reference Book, SAE International and Professional Engineering Publishing, Pennsylvania, 2rd ed., 2004, ch1.

[8] Geris, R., Santos, N. A. C. dos, Amaral, B. A., Maia, I. S. de, Castro, V. D., Carvalho, J. M., Soybean biodiesel - transesterification reaction to practical classes of organic chemistry, Química Nova 30 (5) (2007) 1369-1373. https://doi.org/10.1590/S010040422007000500053 .

[9] Lôbo, I. P., Ferreira, S. L. C., Cruz, R. S. da, Biodiesel: quality parameters and analytical methods, Química Nova 32 (6) (2009) 1596-1608. https://doi.org/10.1590/S0100-40422009000600044.

[10] Soares, B. G., Souza, N. A., Pires, D. X., Organic Chemistry: Theory and Techniques of Preparation, Purification and Identification of Organic Compounds, Guanabara, Rio de Janeiro, 1988, ch.1.

[11] Machado, G. C., Chaves, J. B. P., Antoniassi, R., Composição em ácidos graxos e caracterização física e química de óleos hidrogenados de coco babaçu/ physical and chemical characterization and fatty acid composition of babassu oil, Revista Ceres 53 (308) (2006) 463-466.

[12] Costa Neto, P. R., Rossi, L. F. S., Zagonel, G. F., Ramos, L. P., Production of alternative biofuel to diesel oil through the transesterification of soybean oil used in frying, Química Nova 23 (4) (2000) 531-537. https://doi.org/10.1590/S0100-40422000000400017.

[13] Oliveira, R. S., Borges, M. F., Vieira, A. T., Henrique, M. A., Ribeiro, E. A. M., Bezerra, F. A., Portela, F. M., Pereira, N. R., Assunção, R. M. N., Ruggiero, R., Adsorption of biodiesel contaminants by surface modified bagasse fibers, Química Nova 41 (2) (2018) 121-128. https://doi.org/10.21577/01004042.20170164.

[14] Lace, V. O., Fraga, I. M., Fernandez, J. R. C., Gonçalves, C. R., Obtaining of methyl biodiesel through transesterification through basic catalysis of coconut oil (Cocos Nucifera L), Eclética Química Journal 39 (1) (2014) 192-199. https://doi.org/10.26850/16784618eqj.v39.1.2014.p192-199.

[15] Nascimento, U. M., Vasconcelos, A. C. S., Azevedo, E. B., Silva, F. C., Optimization of biodiesel production from babassu coconut oil with microwave heating, Eclética Química Journal 34 (4) (2009) 37-48. https://doi.org/10.26850/1678-

4618eqj.v39.4.2009.p37-48.

[16] Shimada, Y., Watanabe, Y., Sugihara, A., Tominaga, Y., Enzymatic alcoholysis for biodiesel fuel production and application of the Reaction to oil processing, Journal of Molecular Catalysis B: Enzymatic $\quad 17 \quad(3-5) \quad$ (2002) 133-142. https://doi.org/10.1016/S1381-1177(02)00020-6.

[17] Dias, J. M., Alvim-Ferraz, M. C. M., Almeida, M. F., Comparison of the performance of diferente homogeneus álcali catalysts during transesterification of waste and virgin oils and evaluation of biodiesel quality, $\begin{array}{lllll}\text { Fuel } & 87 & (17-18) & \text { (2008) } & 3572-3578 .\end{array}$ https://doi.org/10.1016/j.fuel.2008.06.014.

[18] Charoenchaitrakool, M., Thienmethangkoon, J., Statistical optimization for biodiesel production from waste frying oil through two-step catalyzed process/ Fuel Processing Technology 92 (1) (2011) 112-118. https://doi.org/10.1016/j.fuproc.2010.09.012.

[19] Barbosa, L. C. A., Espectroscopia infravermelha na caracterização de compostos orgânicos, Editora UFV, Viçosa, 2013. 